\title{
Flexor reflex afferent nerve fibres in man
}

\author{
BHAGWAN SHAHANI \\ From the Department of Neurology, The Churchill Hospital, Oxford
}

SUMMARY Flexor reflex afferent nerve fibres have been identified in the mixed peripheral nerve and measurement of their conduction velocity has been carried out. It has been demonstrated that the flexor reflex afferent fibres have a higher threshold of stimulation than the motor fibres supplying the foot muscles. The effect of conditioning volleys in the flexor reflex afferent fibres on the $\mathrm{H}$ reflex has been determined and reciprocal inhibition of extensor motoneurones has been found to be related to the second component of the flexor reflex.

Kugelberg, in 1948, first investigated the cutaneous afferent nerve fibres involved in the Babinski plantar response (Babinski, 1896, 1898), and the pathological flexor reflex. He noted two different reflex responses with quite separate latencies and came to the conclusion that the first response was due to stimulation of the delta group of A fibres, and that a later, more tonic response was due to $\mathrm{C}$ fibre stimulation in the afferent reflex arc. Pederson (1954) evoked flexor reflex responses in normal subjects and in patients with various lesions of the spinal cord by electrical stimulation of the tibial nerve and found that the latency of reflex responses in general flexors was too brief for the afferent impulse to have traversed the delta group of fibres. Hagbarth (1960) noted that the latency of inhibitory responses in the gluteus maximus and vastus medialis muscles, produced by cutaneous stimulation, gradually decreased as the stimulus was moved upwards in the limb. He estimated the conduction velocity in the afferent fibres to be 33 to $40 \mathrm{~m} / \mathrm{sec}$, a rate which indicated that larger sensory fibres than those of the delta group were involved. After reviewing previous studies on human polysynaptic reflexes, Kugelberg (1962) concluded that attempts to measure the conduction velocity of the flexor reflex afferent nerves in man had as yet produced equivocal results.

To obtain precise information on the integrity or degree of damage to the reflex pathways it is important to identify the afferent fibres mediating the reflex. In the present study these fibres have been identified in the human tibial nerve and an attempt

'Supported by the Association for the Aid of Crippled Children, New York. Present address: Department of Neurology, Massachusetts General Hospital, Boston, Mass. 02114, U.S.A. is made to determine the effects of cutaneous afferent volleys on the spinal motoneurones.

\section{METHOD}

Seven normal healthy subjects, five females and tw $\mathrm{B}$ 웅 males, 14 to 49 years of age, were examined. The room temperature was maintained around $80^{\circ} \mathrm{F}\left(26.6^{\circ} \mathrm{C}\right.$ ) Stimulation was carried out electrically from a DISA Multistim through an isolation transformer. Electromy $\mathbb{E} \mathbb{( \mathbb { D }}$ graphic activity was recorded with clip electrodes whis were connected by a cathode follower input throug $\mathbb{Q}$ Tektronix type 122 preamplifiers to separate beams of $\overrightarrow{9} \overrightarrow{0}$ Nagard cathode ray oscilloscope and filmed on $70 \mathrm{~mm}$ unperforated film. For measuring the conduction velocity of the flexor reflex afferent fibres, the tibial nerve was stimulated at the level of ankle and knee in all the normal subjects. Electrical shocks, consisting of $20 \mathrm{msec}$ trains of $1 \mathrm{msec}$ square wave pulses were delivered with DISA surface bi-polar stimulating electrodes. The stimulus $\mathbb{D}$ amplitude ranged from 10 to $50 \mathrm{~V}$. The reflex response was recorded from the tibialis anterior muscle in the $\overrightarrow{\vec{O}}$ usual manner (Shahani, 1968, 1969). Supramaximal 3 shocks which evoked the reflex response with minimal latency were approximately 2.5 times the thresholdo stimulus.

To study the effects of cutaneous volleys on the $\mathrm{H}_{3}$ reflex, two stimulators (DISA Multistim) were employed, one to give a test stimulus to the tibial nerve in the 3 popliteal fossa, and another to give a conditioning. stimulus to the tibial nerve or the sural nerve at the levelo of the ankle. The test stimulus was a square wave pulse $₹$ with a duration of $0.7 \mathrm{msec}$ and amplitude of 20 to $30 \mathrm{~V}$.을 The conditioning stimulus was a $20 \mathrm{msec}$ train of $1 \mathrm{msec}$ square wave pulses at 500 per sec. The voltage waso altered to deliver weak or strong conditioning shocks. The specially constructed switch triggered both stimula- $N$ tors simultaneously and the test shocks were given over a range of intervals up to $400 \mathrm{msec}$. An interval of 
60 seconds elapsed before the next set of stimuli was delivered. The electrical responses were recorded from the soleus muscle via clip electrodes and a light bandage was applied round them. In this way it was possible to avoid any shift of recording electrodes by muscle movement. The limb was fixed by using a splint specially designed to immobilize the ankle joint. The subjects lay prone on a firm couch during the course of the experiment.

\section{RESULTS}

PATTERN OF REFLEX RESPONSES ELICITED BY STIMULATION OF TIBIAL NERVE It was noted that reflex responses evoked in the tibialis anterior muscle had similar characteristics whether the stimulus was applied to the sole of the foot or directly to the flexor reflex afferent fibres in the tibial nerve. Either form of stimulation evoked flexor reflex responses which were divided into two components (Fig. 1). Similar stimulation of the peroneal nerve at the level of the ankle or knee failed to produce flexor reflexes in the tibialis anterior muscle.

THRESHOLD OF STIMULATION FOR FLEXOR REFLEX AFFERENT FIBRES IN MAN Figure 2 shows electromyographic activity recorded simultaneously from the tibialis anterior muscle (lower tracing in each frame) for recording the reflex response and the short flexors of the toes (upper tracing in each frame) for recording the direct motor response. When low intensity shocks were applied to the tibial nerve at the level of the ankle, only the direct muscle response could be recorded (Fig. 2A). As the strength of stimulus was increased, in addition to late responses recorded in the short flexors of the toes, there appeared a reflex response in the tibialis anterior muscle (Fig. 2C). With further increase in the strength of stimulus the reflex response was more pronounced (Fig. 2D, E, F).

CONDUCTION VELOCITY AND CENTRAL DELAY When the electrical stimulus was applied to the tibial nerve at the level of the ankle, it was possible to deliver supramaximal shocks in all the subjects. The minimal reflex latency (measured from the onset of stimulation) ranged from $52-62 \mathrm{msec}$ with an average of 55 msec. Although it was possible to deliver a supramaximal stimulus to the tibial nerve at the level of the ankle, this was not possible when this nerve was stimulated in the popliteal fossa in six out of seven subjects. Therefore, values for minimal reflex latency could not be estimated in these cases when the tibial nerve was stimulated in the popliteal fossa.

In one subject, who had a relatively low threshold flexor reflex, it was possible to deliver supramaximal shocks to the tibial nerve both at the level of the ankle and the popliteal fossa. Figure 3 shows reflex

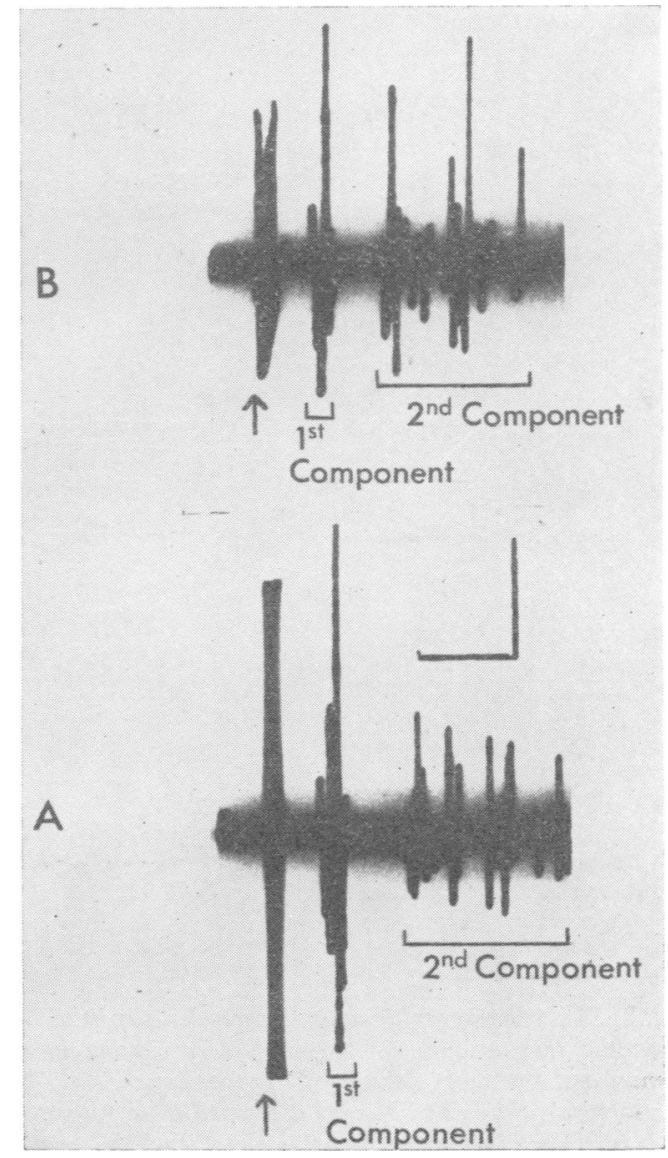

FIG. 1. Two components of the flexor reflex recorded from the ipsilateral tibialis anterior muscle evoked by electrical stimulation, of (A) the sole of the foot and (B) the tibial nerve at the level of ankle. Calibration: horizontal line $100 \mathrm{msec}$. Vertical line $500 \mu \mathrm{V}$. Arrows signify the beginning of the shock artefact.

responses recorded from the tibialis anterior muscle after stimulation of the tibial nerve at the ankle (Fig. 3A) and in the popliteal fossa (Fig. 3B). The minimal latency of the reflex response evoked by stimulation at the level of the ankle was $52 \mathrm{msec}$ and that evoked by stimulation in the popliteal fossa $42 \mathrm{msec}$. Since the distance between the two points of stimulation was $37 \mathrm{~cm}$, the conduction velocity in the afferent fibres mediating the flexor reflex must be $37 \mathrm{~m} / \mathrm{sec}$. With this conduction velocity, the afferent conduction time up to the spinal cord after stimulation at the level of the ankle was calculated as $27 \mathrm{msec}$ for the distance of $1 \mathrm{~m}$ from the ankle to the level of the first lumbar vertebra. With the esti- 


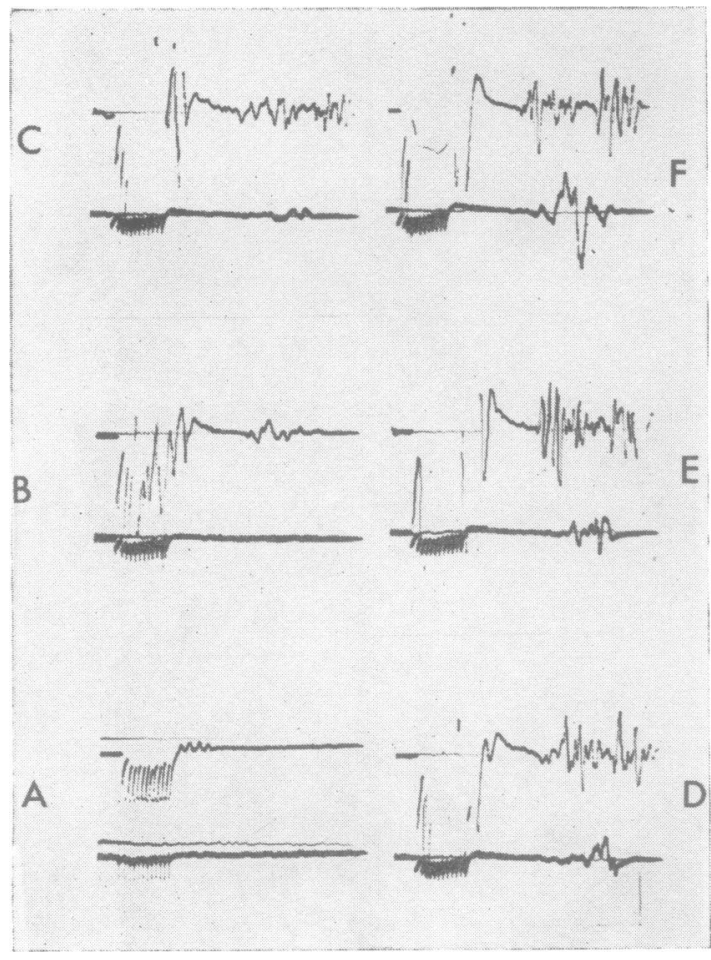

FIG. 2. Electromyographic activity recorded simultaneously from the tibialis anterior muscle (lower tracing in each frame) and the short flexors of the toes (upper tracing in each frame). Stimulus intensity increased from $\mathrm{A}$ to $\mathrm{F}$. The train of stimuli is signified by initial artefact. The horizontal and vertical lines represent $20 \mathrm{msec}$ and $500 \mu \mathrm{V}$ respectively. Stimuli delivered to the tibial nerve at the level of the ankle. (Retouched.)

mated conduction velocity of $55 \mathrm{~m} / \mathrm{sec}$ in the efferent limb of the arc (Kugelberg, Eklund, and Grimby, 1960; Gassel and Trojaberg, 1964) the conduction time up to the level of head of fibula was calculated, which was $13.5 \mathrm{msec}$, to which was added $5.5 \mathrm{msec}$ which was the terminal latency for the direct motor response in the tibialis anterior muscle, evoked by stimulation of the lateral popliteal nerve at the level of the head of the fibula. Therefore, the efferent conduction time must be $19 \mathrm{msec}$. Since the conduction time along the afferent and efferent limbs of the arc was $46 \mathrm{msec}$ and the latency for the reflex response $52 \mathrm{msec}$, there must be central delay of $6 \mathrm{msec}$.

EFFECTS OF CUTANEOUS AFFERENT VOLLEYS ON H REFLEX In the present study, determination of the time course of the recovery curve of the $\mathrm{H}$ reflex to

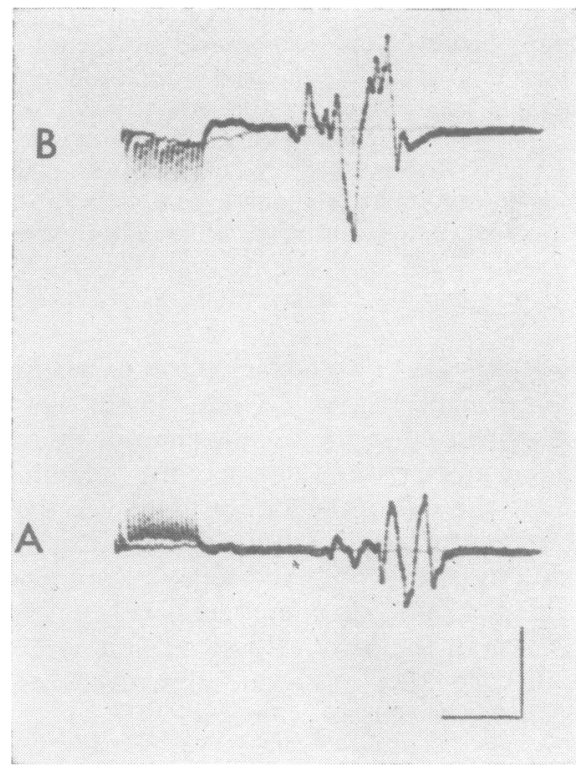

FIG. 3. Flexor reflex recorded from the tibialis anteridf $\infty$ muscle after stimulation of the tibial nerve at the level $\mathrm{A} f \mathrm{~S}$ the ankle (A) and in the popliteal fossa (B). The train \& $\mathrm{f}^{\circ}$ stimuli is signified by the initial artefact. The horizon $1-$ and vertical lines represent $20 \mathrm{msec}$ and $500 \mu \mathrm{V}$ respeg्G tively.

a test stimulus to the tibial nerve in the poplite fossa, at intervals of time after a conditioning volley in the flexor reflex afferent fibres and the low 0 threshold cutaneous afferent fibres has been carried. out (Fig. 4).

With weak tibial nerve stimulation at the ankle, an evident facilitation occurred-that is, the size of the $\mathrm{H}$ reflex was enhanced. This potentiation reached its peak about 100 to $150 \mathrm{msec}$ after the conditioning $\mathbb{\perp}$ stimulus and then gradually returned to normal. With stronger conditioning stimuli and hence stronger activation of flexor reflex afferent fibres, initial facilitation was followed by a prolonged period when the test reflex was diminished. This inhibition was most marked at 150 to $250 \mathrm{msec}$ after the conditioning volleys and then recovered slowly to normal over several hundred msec.

Figure 5 shows the changes in the test reflex when it was preceded by a weak conditioning stimulus to을 the sural nerve. It is quite evident that the early facilitation of the $\mathbf{H}$ reflex noted here is similar to음 that when the conditioning stimuli consisted of low $D$ intensity shocks to the tibial nerve at the ankle.

The tibial nerve at the level of the ankle contains not

\section{DISCUSSION}

Discussion N




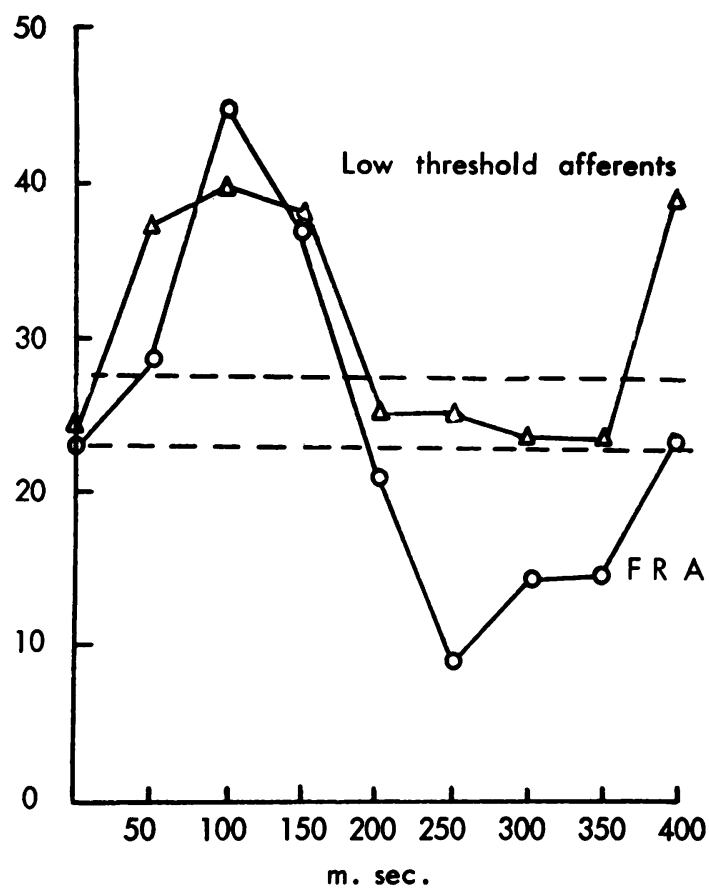

FIG. 4. Changes in the amplitude of $H$ reflex (two superimposed responses) when it is preceded by a conditioning volley in low threshold afferent fibres (triangles) and high threshold afferent fibres (circles). The interrupted line shows the variation in the size of the $H$ reflex in control responses. Abscissa: time interval between the conditioning and test stimulus. Ordinate: arbitrary units for the amplitude of $H$ reflex.

only cutaneous fibres supplying the sole of the foot but also group II and III muscle afferent fibres, which are classified as flexor reflex afferents (Eccles and Lundberg, 1959). Since similar stimulation of the anterior tibial nerve either at the level of the ankle or at the level of head of the fibula failed to elicit the flexor reflex, it was concluded that stimulation of group II and III muscle afferent fibres alone could not be responsible for the reflex responses produced in the tibialis anterior muscle by stimulation of the tibial nerve. Indeed, the marked similarity between the flexor reflex evoked by electrical stimulation of the sole of the foot and that produced by stimulation of the tibial nerve suggests that the afferent fibres concerned are in fact cutaneous nerve fibres supplying the sole of the foot.

In normal man adequate stimulation of the sole of the foot, either mechanical or electrical, results in plantar flexion of the toes, which is accompanied by dorsiflexion at the ankle, and flexion at the knee and

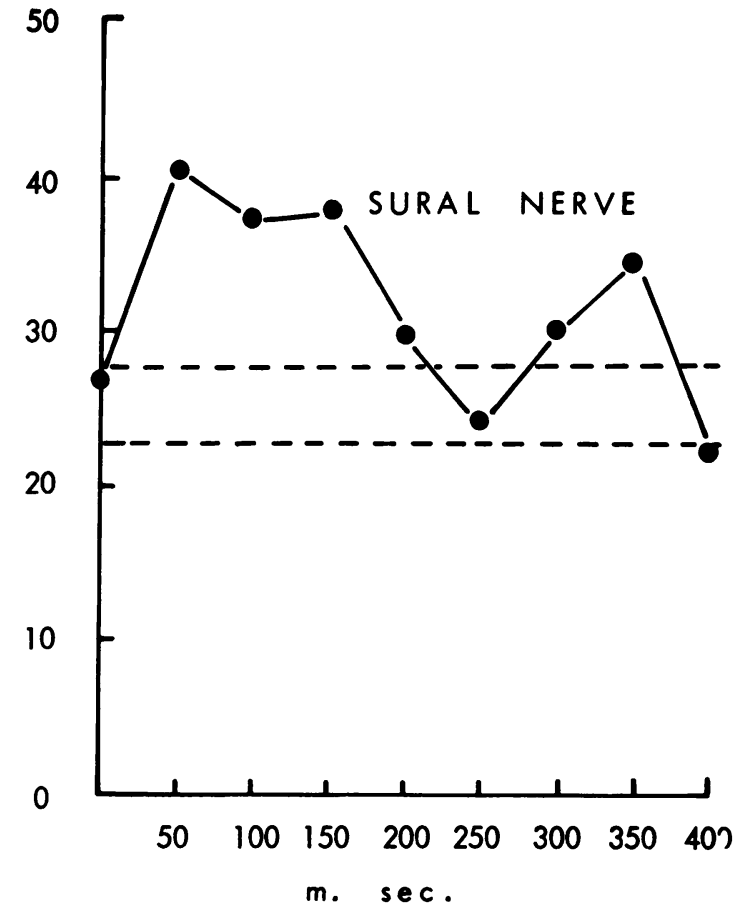

FIG. 5. Changes in the amplitude of the $H$ reflex (two superimposed traces) by a conditioning volley in the sural nerve are signified by closed circles. The interrupted line shows the normal variations in the amplitude of the control $H$ reflex. Abscissa: time interval between the conditioning and test stimulus. Ordinate: arbitrary units signify the amplitude of the $\mathrm{H}$ reflex.

hip (Kugelberg et al, 1960; Grimby, 1963). Therefore it might have been possible to compare the threshold for stimulation of the motor fibres supplying the short toe flexors with that of the sensory fibres producing the flexor responses in the same muscle. This was not done because stimulation of the tibial nerve evokes not only a direct motor response in these muscles but also $F$ responses (Magladery and McDougal, 1950). In order to avoid that confusion, the flexor reflex response was recorded from the tibialis anterior muscle, which in most instances is the first muscle to contract reflexly after electrical stimulation of the sole of the foot or the tibial nerve (Shahani, 1969).

It has already been established that the threshold for stimulation of group I A fibres is lower than that for the stimulation of the motor fibres (Magladery and McDougal, 1950). The present study proves that the threshold for stimulation of the flexor reflex afferent fibres is relatively higher than that of the 
motor fibres. Thus a definite relationship between the threshold of stimulation and the conduction velocity in the human peripheral nerve fibres has been established.

There are probably two main reasons for not being able to deliver supramaximal shocks to the tibial nerve proximally. Firstly, there is an anatomical reason in that the tibial nerve is not as superficial in the popliteal fossa as it is behind the medial malleolus. Secondly the tibial nerve in the popliteal fossa, in addition to cutaneous fibres from the foot and the afferent fibres from the small muscles of the foot, also has large afferent fibres (group I A) from the gastrocnemius-soleus muscle which have inhibitory effects on flexor motoneurones. It is, therefore, not surprising that it should be easier to evoke the flexor reflex when the stimulus to the tibial nerve is delivered more distally before the large sensory fibres from the antagonists of the tibialis anterior muscle join this nerve.

In spite of these difficulties it was possible to measure conduction velocity of the flexor reflex afferent fibres in one subject by direct stimulation at two different sites. Since the minimal reflex latencies evoked by direct stimulation of the afferent fibres in different subjects averaged $55 \mathrm{msec}$, it is fair to assume that the conduction velocity of flexor reflex afferent fibres in man must be in the range of $37 \mathrm{~m} / \mathrm{sec}$. It might have been possible to evoke reflex responses with briefer latency if the flexor muscles were allowed to have a degree of facilitatory voluntary background activity (see Hagbarth, 1960). Although in these conditions accurate measurements are not possible, it appears that the reflex latency is thus shortened by 3 to $4 \mathrm{msec}$. Taking account of these factors, the central delay for the human flexor reflex must be 2 to $3 \mathrm{msec}$, which is similar to that described for the human abdominal reflex (Kugelberg and Hagbarth, 1958) and is comparable with that of spinal polysynaptic reflexes in animals (Eccles and Sherrington, 1931; Creed, Denny-Brown, Eccles, Liddell, and Sherrington, 1932; Lloyd, 1943).

In man, the determination of the recovery curves of the $\mathrm{H}$ reflex using the double stimulation technique has been extensively employed as a method for testing the excitability of the spinal motoneurone pool (Magladery, Teasdall, Park, and Porter, 1951; Teasdall, Park, Porter, and Magladery, 1951; Paillard and Turner, 1953; Paillard, 1959; Táboříková and Sax, 1969). The alteration in the motoneurone excitability produced by conditioning volleys in the tibial nerve at the level of the ankle was also noted by Teasdall et al. (1951). When the stimulus was weak only early facilitation was noted, whereas if the strength of stimulus was increased, the initial enhancement of the test reflex was followed by inhibition with gradual recovery to normal. These changes in the motoneurone excitability were attributed to conditioning by impulses arising in the axons innervating the synergistic muscles-that is, the small muscles of the foot. From latency measurements, it was shown that these conditioning effects arose through the intermediary of interneurones.

Since the sole of the foot is the best receptive field for both the flexor reflex and the extensor thrust, the tibial nerve must contain cutaneous fibres mediating both these reflexes. It is possible, therefore, that stimulation of low threshold cutaneous afferent fibres supplying the sole of the foot could produce facilitation of the extensor motoneurones. This, in fact, appears to be so because sural nerve stimulation with low intensity shocks produced similar facilitation. With increasing strength of stimulation, not only large cutaneous fibres which produce facilitation but high threshold afferent fibres (flexor reflex afferents) are stimulated. The latter produce facilitation of flexor motoneurones with reciprocal inhibition of extensor motoneurones. From the time course of the inhibitory effects produced by flexor reflex afferent volleys it is apparent that these effects areo most marked at a time when excitation of flexoळ motoneurones would produce the second component of the flexor reflex. It has already been shown tha it is the second component of the flexor reflex which results in withdrawal movement (Shahani, 1968 1969) and in the light of that observation it is nof surprising that the reciprocal inhibition of the. extensor motoneurones is related to the secons component.

There has been a general tendency to interpret all the findings of the $\mathrm{H}$ reflex investigations as if the alteration in the excitability of extensor motoneurones is produced only by a volley of muscle afferent impulses when the conditioning and test shocks are delivered to the tibial nerve in the popliteal fossa (Magladery et al., 1951; Paillard, 1959; Tábaříková and Sax, 1969). It must be emphasised, however, that the tibial nerve contains not only muscle afferent fibres from the calf muscles and the small muscles of the foot, but also cutaneous sensory fibres supplying the sole of the foot and the extensor surface of the leg. Since cutaneous stimulation of the lower limb can evoke ipsilateral extensor or flexor reflex (Hagbarth, 1952, 1960), the afferent input from the sensory fibres mediating these reflexes must have a profound effect on the excitability of the extensor motoneurones. The present study has demonstrated that stimulation of low threshold cutaneous afferent fibres produces predominantly facilitatory effects in the extensor motoneurones in $\stackrel{\sigma}{\sigma}$ man. It is possible that these fibres may be responsible for ipsilateral extensor reflexes in the human 
lower limb. On the other hand, stimulation of high threshold cutaneous afferent fibres in man not only evokes the flexor reflex but produces reciprocal inhibition of the extensor motoneurones.

I would like to express my grateful appreciation to Professor W. Ritchie Russell for his constant encouragement and advice. I also thank Dr. G. Rushworth for giving me laboratory facilities.

\section{REFERENCES}

Babinski, J. (1896). Sur le réflexe cutané plantaire dans certaines affections organiques du système nerveux central. C.R. Soc. Biol. (Paris), 3, 207-208.

Babinski, J. (1898). Du phénomène đes orteils et de sa valuer semiologique. Sem. méd. (Paris), 18, 321-322.

Creed, R. S., Denny-Brown, D., Eccles, J. C., Liddell, E. G. T., and Sherrington, C. S. (1932). Reflex Activity of the Spinal Cord. Clarendon Press: Oxford.

Eccles, J. C., and Sherrington, C. S. (1931). Studies on the flexor reflex. I. Latent period. Proc. roy. Soc. B., 107, 511-534.

Eccles, R. M., and Lundberg, A. (1959). Synaptic actions in the motoneurons by afferents which may evoke the flexion reflex. Arch. ital. Biol., 97, 199-221.

Gassel, M. M., and Trojaborg, W. (1964). Clinical and electrophysiological study of the pattern of conduction times in the distribution of the sciatic nerve. J. Neurol. Neurosurg. Psychiat., 27, 351-357.

Grimby, L. (1963). Normal plantar response: integration of flexor and extensor reflex components. J. Neurol. Neurosurg. Psychiat., 26, 39-50.

Hagbarth, K.-E. (1952). Excitatory and inhibitory skin areas for flexor and extensor motoneurones. Acta physiol. scand., 26, Suppl. 94, 1-58.

Hagbarth, K.-E. (1960). Spinal withdrawal reflexes in the human lower limbs. J. Neurol. Neurosurg. Psychiat., 23, 222-227.

Kugelberg, E. (1948). Demonstration of A and C fibre components in the Babinski plantar response and the pathological flexion reflex. Brain, 71, 304-319.
Kugelberg, E. (1962). Polysynaptic reflexes of clinical importance. Electroenceph. clin. Neurophysiol., Suppl. 22, 103-110.

Kugelberg, E., Eklund, K., and Grimby, L. (1960). An electromyographic study of the nociceptive reflexes of the lower limb. Mechanism of the plantar responses. Brain, 83, 394-410.

Kugelberg, E., and Hagbarth, K. E. (1958). Spinal mechanism of the abdominal and erector spinae skin reflexes. Brain, 81, 290-304.

Lloyd, D. P. C. (1943). Neuron patterns controlling transmission of ipsilateral hind limb reflexes in the cat. $J$. Neurophysiol., 6, 293-315.

Magladery, J. W., and McDougal, D. B., Jr. (1950). Electrophysiological studies of nerve and reflex activity in normal man. I. Identification of certain reflexes in the electromyogram and the conduction velocity of peripheral nerve fibres. Bull. Johns Hopk. Hosp., 86, 265-290.

Magladery, J. W., Porter, W. E., Park, A. M., and Teasdall, R. D. (1951). Electrophysiological studies of nerve and reflex activity in normal man. IV. The two-neurone reflex and identification of certain action potentials from spinal roots and cord. Bull. Johns Hopk. Hosp., 88, 499-519.

Maglađery, J. W., Teasdall, R. D., Park, A. M., and Porter, W. E. (1951). Electrophysiological studies of nerve and reflex activity in normal man. V. Excitation and inhibition of two-neurone reflexes by afferent impulses in the same nerve trunk. Bull. Johns Hopk. Hosp., 88, 520-537.

Paillard, J. (1959). Functional organization of afferent innervation of muscle studied in man by monosynaptic testing. Amer. J. phys. Med., 38, 239-247.

Paillard, J., and Turner, M. (1953). Some views about an electrophysiological study of the reflex activity in man. Electroenceph. clin. Neurophysiol., 5, 467.

Pederson, E. (1954). Studies on the central pathway of the flexion reflex in man and animal and changes in the reflex threshold and the circulation after spinal transection. Acta psychiat. scand., Suppl. 88, 3-81.

Táboříková, H., and Sax, D. S. (1969). Conditioning of H-reflexes by a preceding subthreshold $\mathrm{H}$-reflex stimulus. Brain, 92, 203-212.

Shahani, B. (1968). Effects of sleep on human reflexes with a double component. J. Neurol. Neurosurg. Psychiat., 31, 574-579.

Shahani, B. (1969). A Study in Human Reflexes. Ph.D. thesis, Oxford University. 